\title{
How price sensitive is letter advertising mail in the UK? ${ }^{1}$
}

Frédérique Fève (IDEI, Toulouse School of Economics), Thierry Magnac (IDEI, Toulouse School of Economics), Leticia Veruete-McKay (Royal Mail Group) and Soterios Soteri (Royal Mail Group)

\section{Introduction}

Addressed letter advertising mail in the UK accounted for almost one-fifth of total UK advertising expenditure in 2003 but by the end of 2017 this figure had declined to approximately half this level ${ }^{2}$. Over the same time period, newspaper and magazine physical print media expenditure in advertising declined to an even greater extent while digital advertising spent increased from a near zero figure to almost half of total UK advertising expenditure.

The better performance of addressed letter advertising mail (henceforth referred to as direct mail) relative to other print media is likely due to a number of reasons. Two important and interrelated factors are, first, the extent to which advertisers using print media are willing to adopt alternative digital media and, second, the degree to which the different advertising media are believed to influence recipient behavior. In order to assess the latter, a number of postal operators have used new and innovative research techniques (such as neuro-marketing methods) to show that mail continues to remain an effective medium. Much of these research findings are available in the public domain and Althen et al. 2017 provides a good summary of this literature. More limited evidence is available on factors that postal operators have some control over. One key factor is price, which can be used to influence the demand for direct mail. Veruete-Mckay et al. 2011 provide estimates for the UK direct mail market price elasticity that lie in the range -0.7 to -1.4 and Bzhilyanskaya et al. 2015 estimate own-price elasticities for USPS advertising mail product ${ }^{3}$ of -0.9 and net of switching to other products of -0.7 . While these findings are useful in terms of informing high level direct mail and product pricing strategies, they are less so with respect to devising customer focused business initiatives in a competitive media market.

The econometric analysis contained in this article is a first attempt to bridge this information gap in the postal literature. In particular, we use a large data set covering Royal Mail addressed advertising to customers over the period 2011 to 2017 to estimate price elasticities that take into account customer characteristics such as sector and firm size. Section 2 describes the data and estimation methodology for modelling price elasticities. Sections 3 and 4 contain results and section 5 provides a summary and conclusion.

\section{Modelling advertising mail demand}

Letter demand functions can be estimated as the relationship between letter traffic volumes, denoted by $Q$, for different types of letter mail products, denoted by $j$, sent by different customers, each denoted by $i$, the level of prices charged to send mail, denoted by $P$, at a

\footnotetext{
${ }^{1}$ The views expressed in this paper are those of the authors and do not necessarily reflect those of their affiliated organizations.

${ }^{2}$ Estimates informed by figures from various World Advertising Research Center (WARC) Expenditure Reports.

${ }^{3}$ USPS estimated price elasticities refer to Standard Regular mail which is mainly used to send advertising mail.
} 
specific point in time, $t$, and environmental (exogenous) variables denoted by $X$. Where data are available on these variables for $n$ customers, empirical analysis can be undertaken of the demand function, which can be written as:

$$
Q_{i j t}=f\left(P_{i j t}, X_{i j t}, u_{i j t}\right) \quad i=1, \ldots . . n \quad j=1, \ldots, m \text { and } t=1, \ldots, T
$$

where $u$ represents a random error term.

To the best of our knowledge, most econometric studies of letter demand that have been undertaken do not explicitly include the customer dimension, $i$, within their models. Instead, they have tended to examine the demand for individual products or groups of products over time (see for example Bzhilyanskaya et al. 2015 and Veruete-Mckay et al. 2011). While such studies are highly useful in terms of examining letter demand at an aggregate level they are less so in helping to devise customer focused strategies in competitive segments, such as advertising mail.

One reason for the absence of customer focused demand functions may be the lack of high quality customer time series data or, possibly, the availability of such data to researchers. In contrast, this article explicitly includes a customer dimension and undertakes econometric analysis that uses a rich data set of Royal Mail retail customers to estimate letter demand functions consistent with (1) for addressed letter advertising traffic. The data covers eight product categories $(m=8)$ consisting of two sortation levels (low and high sort) and two speeds of delivery (second class and economy) for each of two letter format sizes (standard and large). Information was available for $2640(=n)$ retail addressed advertising customers for the period July 2011 to September 2017 and the data was aggregated on a quarterly time period basis, $t$. Customer prices for a specific letter product for each quarter, period, $P_{i j t}$, were derived by dividing customer revenue data, $R_{i j t}$, by the corresponding volume, $Q_{i j t}$. The customers contained in this data accounted for almost a quarter of all addressed advertising sent in the UK over the time period examined and excluded mail sent via access operators as the vast majority of these customers could not be identified.

A traditional parametric econometric approach was used to estimate the demand function (1) considering a log-linear model, similar to Fève et al, (2018). This is a commonly adopted approach whose parameter estimates can be immediately interpreted as elasticities. The model included letter mail volumes $(Q)$, prices $(P)$ and various environment variables $(X)$ as a set of dummy variables to account for exogenous factors, heterogeneity in sender characteristics and differences in products. In particular, three sets of dummy variables were included. First, time series dummies, dtime, to capture the net impact of exogenous factors at each point in time, such as macro-economic variables, e-substitution and other external events. An alternative approach would have been to include additional variables into the model to explicitly estimate these effects, however the inclusion of time dummies is a common and more general approach that captures the net effect of all exogenous variables and allows us to more clearly focus attention on the parameter estimates for price which is our primary objective ${ }^{4}$. Second, customer characteristic dummies to account for differences in demand among $10(=k)$ sender sector groups, dsector, and the size of each sender

\footnotetext{
${ }^{4}$ Model specifications including various economic activity and other variables were initially included and yielded similar results.
} 
organizations, size, as measured by the number of employees. Third, shift dummies, dproduct, were included to capture differences in sender demand for different letter products.

Two model specifications, A and B, were estimated using these variables in order to provide insights into the heterogeneity of price elasticities by customer sector and size and took the following form:

Model A

Model B

$$
\begin{aligned}
\ln \left(Q_{i j t}\right)= & \alpha+\beta_{k} \text { dsector }_{k} \ln \left(p_{i j t}\right)+\gamma \ln \left(\text { size }_{i}\right)+\delta_{k} \text { dsector }_{k} \\
& +\lambda_{j} \text { dproduct }_{j}+\mu_{t} \text { dtime }_{t}+v_{i j t}
\end{aligned}
$$

$$
\begin{aligned}
\ln \left(Q_{i j t}\right)= & \alpha+\beta \ln \left(p_{i j t}\right)+\gamma_{1} \ln \left(\text { size }_{i}\right) \ln \left(p_{i j t}\right)+\gamma\left(\ln \left(\text { size }_{i}\right)+\delta_{k} \text { dsector }_{k}\right. \\
& +\lambda_{j} \text { dproduct }_{j}+\mu_{t} \text { dtime }_{t}+v_{i j t}
\end{aligned}
$$

with all variables in logarithmic form denoted by $\ln ($ ).

Model A allows for customer sector dummy interaction terms with the price variable and yields estimated price elasticities that differ for each of the individual $k$ customer sector groups (that is, price elasticities are estimated for $\beta_{k=1}, \ldots, \beta_{k=10}$ from expression (2)). Where the sectors considered are: Commercial Services, Finance and Insurance, Information and Communications, Manufacturing, Other, Public Services, Postal Services, Retailers and Wholesalers, Transportation and Storage and Utilities. In contrast, Model B provides price elasticity estimates that vary by customer size and equal to $\beta+\gamma_{1} \ln ($ size) in expression (3), where "size" is measured by the number of employees of the customer centered at its mean value, such that the price elasticity for the mean customer is $\beta$.

\subsection{Dealing with endogeneity}

The advertising letter price variable in both the estimated demand models $\mathrm{A}$ and $\mathrm{B}, p_{i j t}$ is by construction highly likely to be an endogenous variable because it is derived using information on volume data which is the dependent variable in the demand equation. Any measurement error in volumes will therefore contaminate the measure of prices and introduce a spurious correlation between the left-hand side variable and the right-hand side variables (see for instance, Borjas, 1980). Furthermore, the use of price discounts to incentivize customers to mail additional volumes (such as Royal Mail incentive for growth schemes) means there is likely to be a degree of endogeneity present because price discounts are probably positively correlated with volumes. Given that price is constructed by dividing revenues by volumes, this spurious correlation is likely to be negative.

In order to address this issue, Instrument Variable (IV) estimation techniques were adopted to correct for endogeneity (see for instance Davidson and McKinnon, 2004). In the first stage we used two instrumental variables, the average sectoral prices as constructed from the data and the standard rate card price that was available at the time. However, we tested and rejected overidentifying restrictions when using both instruments and had to choose between the two. On that basis, the rate card price is likely to be the least affected by customer shocks, customer heterogeneity or measurement errors this variable was adopted. 
The estimation proceeded as follows. First, an instrumental variable auxiliary equation was obtained by regressing the endogenous variable $\ln \left(p_{i j t}\right)$ on the $\log$ of rate card prices and other control variables appearing either in model A or model B. Second, the two-stage least squares (2SLS) estimates of models A and B were obtained by using residuals from the instrumental variable equation. This numerical procedure is equivalent to the more common procedure which replaces the endogenous variable by its predictor derived from the instrumental equation (see Davidson and McKinnon, 2004). This is a more convenient procedure because the endogenous price variable $\ln \left(p_{i j t}\right)$ enters not only as a variable on the right hand side of Models $\mathrm{A}$ and $\mathrm{B}$ but also through its interactions with either sectoral dummies in Model A or log-size in model A. This is why the 2SLS estimates below were derived by including not only residuals of the instrumental variable equation in levels but also their interaction with sectoral dummies or log-size depending on which model was estimated. Furthermore, in order to more fully exploit variation in the data, separate instrumental regressions were estimated for each of the ten sender sector groups and those residuals constructed from these regressions were included in the second stage of the estimation procedure.

This approach yielded correctly signed and, in most cases, statistically significant estimated price elasticities which are reported in section three. In terms of the actual models estimated, these are equivalent to estimating the following models using ordinary least squares:

Model A

$$
\begin{aligned}
\ln \left(Q_{i j t}\right)= & \alpha+\beta_{k} \text { dsector }_{k} \ln \left(p_{i j t}\right)+\gamma \ln \left(\text { size }_{i}\right)+\delta_{k} \text { dsector }_{k} \\
& +\lambda_{j} \text { dproduct }_{j}+\mu_{t} \text { dtime }_{t}+\varphi_{k} \text { dsector }_{k} \hat{u}_{i j t}+v_{i j t}
\end{aligned}
$$

Model B

$$
\begin{aligned}
\ln \left(Q_{i j t}\right)= & \alpha+\beta \ln \left(p_{i j t}\right)+\gamma_{1} \ln \left(\text { size }_{i}\right) \ln \left(p_{i j t}\right)+\gamma\left(\ln \left(\text { size }_{i}\right)+\delta_{k} \text { dsector }_{k}\right. \\
& +\lambda_{j} \text { dproduct }_{j}+\mu_{t} \text { dtime }_{t}+\varphi_{k} \ln \left(\text { size }_{i}\right) \hat{u}_{i j t}+v_{i j t}
\end{aligned}
$$

in which $\hat{u}_{i j t}$ is the residual constructed from the instrumental regressions in each sector with ln $\left(p_{i j t}\right)$ as the dependent variable and as explanatory variables all the respective variables included in each of the estimated models (3) and (4). ${ }^{5}$

\section{Estimated price elasticities for retail addressed advertising mail}

Table 1 reports the estimated coefficients for the price terms and their respective standard errors for models A and B. It should be noted that the estimated price elasticities reported in this table relate to customers who mainly used Royal Mail retail advertising products during the time period analyzed.

\footnotetext{
${ }^{5}$ Note that $\ln (p)$ in (3) and (4) is equal to the sum of the instrumental variable for the price variable, $\ln \left(\hat{p}_{i j t}\right)$ and the residual constructed from the instrumental regression $\hat{u}_{i j t}$. Specifying the model as in (3) and (4) can be considered to be more transparent as the test of endogeneity is performed directly by examining the estimated coefficients associated with $\hat{u}_{i j t}$.
} 
The two models provide insights into retail customer price elasticities via different lenses. The results reported in model A suggest that price elasticities differ substantially by sector and the hypothesis that they are all equal is strongly rejected using a Fisher test. The estimated sector price elasticities can be grouped into four broad categories. First, sectors with customers that, on average, exhibit a high degree of responsiveness to price changes include the Utilities, Finance and Insurance and Postal Services organizations, with estimated price elasticities in the range -2.6 to -1.1 . Second, sectors with estimated price elasticities that have an absolute magnitude of just below unity, on average, around - 0.8 to -0.9 include customers from Public Services and Retail and Wholesale sectors. Third, those with relatively lower estimated price elasticities which, on average, are around -0.5 to -0.6 and include the Commercial Services, Information and Communications and Manufacturing sectors. Fourth, sectors in which price effects are not statistically significant include Transport and Storage and Other sectors with estimated price elasticities of -0.1 and -0.3 respectively. The absence of statistically significant results for the fourth group may partly be due to the weakness of the instrument used for prices which is derived from rate card information and for the Other sector may also be related to the highly heterogeneous nature of customers contained within this group.

Model B examines the same customer data via an alternative lens and suggests that retail advertising customer price elasticities tend to increase in absolute terms with customer size and that the average price elasticity is around -0.71. This estimate is close to the aggregation of the individual sector price elasticities reported in model A weighted by their respective sector observations ${ }^{6}$ which is -0.60 . However, the results reported in Table 1 also indicate that, in general, larger firms tend to be more price sensitive than smaller firms. This may be due to the greater flexibility that larger firms have with respect to access to other media advertising channels, such as digital or television. The demand elasticity in Model $\mathrm{B}, \varepsilon$, is estimated to be a function of customer size (measured by the number of employees of the organization sending mail) and the formulae is $\varepsilon=-0.71-0.06 \ln ($ size $)$. On average, the estimated price elasticity for a relatively small company (say 20 employees) is equal to around -0.66 and for a very large firm (say, more than 2000 employees) around -0.94 .

\footnotetext{
${ }^{6}$ The relative weights for the sectors where Commercial Services (9\%), Finance and Insurance (2\%), Information and Communications (38\%), Manufacturing (6\%), Other (16\%), Public Services (4\%), Postal Services (1\%), Retailers and Wholesalers $(22 \%)$, Transportation and Storage $(2 \%)$ and Utilities $(<1 \%)$.
} 
Table 1: Retail addressed advertising mail estimated price elasticities

\begin{tabular}{|c|c|c|c|c|c|}
\hline \multicolumn{2}{|l|}{ Market sector } & \multicolumn{2}{|c|}{ Model A } & \multicolumn{2}{|c|}{ Model B } \\
\hline \multicolumn{4}{|c|}{ Estimated price elasticities for sector $\beta_{k}$} & \multicolumn{2}{|c|}{$\begin{array}{l}\text { Estimated aggregate price elasticity }(\beta) \\
\text { varies by customer size }(\gamma)\end{array}$} \\
\hline Commercial services & & $-0.60^{* * *}$ & 0.26 & & \\
\hline Finance \& insurance & & $-1.52 * * *$ & 0.30 & & \\
\hline Information and communic & tions & $-0.52 * *$ & 0.26 & & \\
\hline Manufacturing & & $-0.48^{*}$ & 0.26 & $\beta=-0.71 * * *$ & 0.21 \\
\hline Other & & -0.26 & 0.24 & & \\
\hline Public Services & & $-0.88 * * *$ & 0.28 & $\gamma=-0.06^{* * *}$ & 0.01 \\
\hline Postal services & & $-1.11 * * *$ & 0.43 & & \\
\hline Retailers and wholesalers & & $-0.84 * * *$ & 0.23 & & \\
\hline Transportation and storage & & -0.11 & 0.28 & & \\
\hline Utilities & & $-2.60 * * *$ & 0.52 & & \\
\hline $\begin{array}{l}\text { No. of observations } 34,075 \\
\mathrm{R}^{2}=0.34 \\
\text { Adjusted } \mathrm{R}^{2}=0.34\end{array}$ & $\begin{array}{l}\text { F }(61, \\
\text { Prob } \\
\text { RMS }\end{array}$ & $\begin{array}{l}34,013)=287.2 \\
>F=0.0000 \\
E=1.3159\end{array}$ & & $\begin{array}{l}\text { No. of obs. } 34,075 \\
\mathrm{R}^{2}=0.34 \\
\text { Adjusted } \mathrm{R}^{2}=0.34\end{array}$ & $\begin{array}{l}F(61,34,029)=383.5 \\
\text { Prob }>F=0.0000 \\
\text { RMSE }=1.3191\end{array}$ \\
\hline
\end{tabular}

\section{Estimated price elasticities for sub-sample groups of addressed advertising customers}

In order to obtain further insights into the price sensitivity of retail advertising customers, Model B was estimated for four subsample groups. In particular, the customer sample of 2640 organizations was partitioned into four categories: Stayers, Movers, Round-trippers and Occasional. These specific categories were chosen to examine the impact of customers registering different patterns of zero volumes in the sample period available and the results obtained should only be viewed as descriptive and directional in nature to the total sample. We estimate the same model as before under the assumption that these samples are not selected or censored. A full correction for selection is out of the scope of this article and left for further research because instruments for selectivity corrections are absent. In particular, we do not observe the prices of competitors. An interesting implication of the hypothesis of the absence of selection, however, is that elasticities in all subsamples should be the same. As they are not, this exploratory section shows the limitations of this simple approach although it remains informative as a descriptive device.

The Stayers included 376 customers who were defined as continuous users of Royal Mail retail advertising product until the end of the period examined and included new customers who entered the sample prior to the end date. Organizations in the Movers category included those who stopped using retail advertising products at some point prior to the end of the sample period, including those who may have moved to sending advertising letters via competitor access services, and accounted for 789 customers $^{7}$. Round-trippers were defined as

\footnotetext{
${ }^{7}$ In general, if a customer switched from using a Royal Mail retail product to sending mail via an access competitor, which is most likely to be the case when we observe a continuous string of zero values for a retail advertising customer, then all information on the customer becomes unobservable.
} 
customers who continued to use retail advertising products until the end of the sample period but displayed some periods of time when they did not send any retail advertising mail and accounted for 312 customers. Finally, the Occasional users group included those who infrequently sent retail advertising mail (four times or less) over the period examined and numbered 1163 customers.

The results reported in Table 2 can potentially provide some useful insights to postal operators when considering customer focused pricing strategies while keeping in mind the limitations of the approach due to selection and censorship. In particular, they suggest that advertising mail senders who tend to be Stayers (that is loyal customers with a pattern of repeated purchase) are, on average, likely to be highly sensitive to price changes (with a mean price elasticity of demand, $\beta$, equal to -1.9). This result also seems to be the case for Occasional users of advertising mail, who are also estimated to, on average, be sensitive to price changes (with a mean price elasticity of demand, $\beta$, equal to -1.5 ), although unlike the Stayer group the sensitivity to price for larger customers is estimated to be not statistically significant. In contrast, the mean estimated price elasticities for Movers and Round-trippers $(\beta)$ reported in Table 2 were both low and not statistically significant, although there was some evidence to suggest that the former's elasticity increased somewhat with the size of customer $(\gamma)$.

The Mover and Round-tripper results are somewhat puzzling, in that one would expect the estimated price elasticities for these groups to be at least as high (in absolute terms) as the Stayers category. However, as previously mentioned, the results reported in Table 2 are likely to depend on the criteria used to select the sub-groups over the time period examined. It is therefore likely to be the case that the low and statistically insignificant estimated price elasticity for Movers may be due to selection bias. In particular, this group primarily consists of customers who have switched away from using Royal Mail retail advertising mail products to sending letter mail via a downstream access competitor. Under such circumstances, the volume of advertising letters sent by customers who switch to a Royal Mail competitor, which is likely to be the vast majority of the Movers customer sample, will be recorded as a continuous string of zero values (as information sent via competitors is no longer available to Royal Mail). One of the main drivers underpinning this switching behavior will be competitor customer prices which tend to be individually negotiated and sensitive commercial information that is not publicly available. The absence of competitor downstream access prices is therefore likely to be an important factor contributing to the low and non-significant price elasticity estimate for the Movers category. A similar point applies to the price elasticity estimate for Round-trippers. 
Table 2. Retail addressed advertising mail estimated price elasticities for sub-groups of customers

\begin{tabular}{lllcc}
\hline \multicolumn{1}{c}{ Stayers } & Movers & Round-trippers & Occasional \\
$\beta$ & $-1.88^{* * *}$ & -0.25 & -0.26 & $-1.47 * * *$ \\
$\gamma$ & $(0.24)$ & $(0.32)$ & $(0.25)$ & $(0.12)$ \\
& $-0.04 * *$ & $-0.09 * * *$ & -0.02 & -0.02 \\
& $(0.02)$ & $(0.02)$ & $(0.02)$ & $(0.03)$ \\
\hline No of obs. & 14,652 & 11,534 & 5,041 & 2,787 \\
$\mathrm{R}^{2}$ & 0.3629 & 0.3559 & 0.2928 & 0.4292 \\
Adj R $^{2}$ & 0.3609 & 0.3535 & 0.2968 & 0.4201 \\
$\mathrm{~F}-$ test & $\mathrm{F}(45,14325)=185.2$ & $\mathrm{~F}(42,11491)=151.2$ & $\mathrm{~F}(43,4997)=48.12$ & $\mathrm{~F}(44,2742)=46.9$ \\
RMSE & 1.3301 & 1.2822 & 1.2364 & 1.2061 \\
\hline \multicolumn{2}{l}{ Notes: *denotes statistically significant at $10 \%$ level, ** at 5\% level, *** at 1\% level. Figures in parentheses } \\
are standard errors.
\end{tabular}

\section{Summary and conclusions}

Addressed letter advertising mail in the UK as a share of total advertising expenditure has halved over the past 15 years, while physical print media (newspapers and magazines) have declined to an even greater extent and digital advertising increased to represent around half of total UK advertising spend. Postal operators have responded to this challenge by proving the effectiveness of advertising letter mail through new and innovative research techniques (such as neuro-marketing methods) to show that mail continues to remain a relevant medium even in a digital epoch. However, the extent to which advertising mail will remain a widespread medium will also depend on the pricing strategies adopted by postal operators.

This article examined the behavior of Royal Mail retail customers over the period 2011 to 2017 to provide insight into the degree to which they are responsive to price changes and the extent to which this differs by customer sector and firm size. It should be noted that the price elasticities estimated in section 3 are conditional on the sample of customers analyzed (that is customers using retail advertising products over the period examined) and the subsamples examined, therefore, care should be taken in interpreting and using these results. With this qualification in mind, the estimated elasticities suggest that the overall price elasticity for retail customers is around -0.7 but tend to increase in absolute value by customer size. In addition, the econometric analysis undertaken also suggests that some segments of customers are likely to be substantially more price sensitive than others. In particular, retail customers operating in the Finance and Insurance and Utilities sectors are estimated to be highly sensitive to price movements with estimated price elasticities of -1.5 and -2.6 respectively.

Additional analysis was undertaken for customer sub-samples. However due to potential issues related to selection bias these results should only be viewed as directional in nature. In particular, this analysis suggested that organizations that very frequently or very infrequently send retail advertising mail are likely to be highly sensitive to price changes (with estimated price elasticities in the range of around -1.5 to -2.0 ). In contrast, estimated price elasticities were low and not statistically significant for customers that stopped using retail advertising mail, referred to as Movers in our analysis, or tended to intermittently not send mail, referred to as Round-trippers. The low estimated price elasticities for the latter two categories is a 
puzzling result and we suspect this may be due to selection bias resulting from the absence of information on customers who switch from sending advertising mail with Royal Mail's retail product range to sending mail via an access competitor (and therefore become non observable in our data) and also due to the absence of competitor price information.

In conclusion, the results contained in this article provide some indicative estimates of customer profiles and characteristics that are likely to be more sensitive to price movements and can help to inform advertising mail customer pricing strategies. However, as indicated, the estimated elasticities reported are conditional on the sample examined and sub-samples selected. An avenue worthy of further research in this area would be to build on the results contained in this article for retail customers by explicitly taking into account the impact of missing values due to customers switching to access operators and avoiding the impact of any potential bias resulting from the selection of firms belonging to specific sub-sample groups.

\section{References}

Althen, J., J. Ten-Kate, A. Stafford and K. Thresher (2017), Mail as a branding tool: Recent research and the path forward. Presented at the 25th Conference on Postal and Delivery Economics, Barcelona, Spain, May 2017

Borjas, G. J. (1980). The relationship between wages and weekly hours of work: The role of division bias. The Journal of Human Resources, 15(3), 409-423.

Bzhilyanskaya, L.Y., M. Cigno and E.S. Pearsall (2015. "A Branching AIDS Model for Estimating U.S. Postal Price Elasticities”. In M.A Crew and T.J. Brennan (eds.), Postal and Delivery Innovation in the Digital Economy. Springer International Publishing Switzerland, 91-113.

Davidson R. and MacKinnon J., 2004, Econometric Theory and Methods, Oxford University Press. Fève, F., T. Magnac, S. Soteri and L. Veruete-McKay (2018), "Price Elasticities and Factors Driving International Contract Export Mail Sent from the UK to Western European Countries". In P.L. Parcu, T. Brennan and V. Glass (eds.), The Contribution of the Postal and Delivery Sector, Springer International Publishing AG, 299-310.

Veruete-McKay, L., S. Soteri, J. Nankervis, F. Rodriguez (2011), 'Letter traffic demand in the UK: an analysis by product and envelope content type', Review of Network Economics, 10(3). 